\title{
Supply chain collaboration and performance: an empirical study of maturity model
}

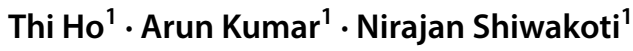

Received: 24 March 2019 / Accepted: 10 March 2020 / Published online: 20 March 2020

(c) Springer Nature Switzerland AG 2020

\begin{abstract}
Supply chain collaboration (SCC) is a competitive tool used to improve the business performance of an organisation and the entire supply chain. Firms have therefore strived to achieve a greater collaboration level; however, most of the collaboration initiatives end up in failures. It is confirmed that how SCC impacts performance and how it leads to higher levels of performance are not well understood in real world. Especially, there is a dearth of empirical research on the analysis of the specific industry to minimize the chance of failure of implementation phase. Given these limitations, this paper aims to explore in-depth the relationship of SSC mechanisms; maturity level in particular; and performance outcomes in a specific industry. A maturity model for SCC based on capability maturity model integration approach is used to evaluate the current practices as well as to measure the maturity level of SCC of textile and garment case studies. In order to analyse how different maturity levels impact the performance, actual data on performance indicators was collected. The findings show the applicability and usefulness of the model. The relationship between SCC mechanisms and performance is confirmed with the role of internal collaboration as mediators. The in-depth exploration has also indicated that internal collaboration, including information integration and operations management, moderates the relationship between external integration and performance.
\end{abstract}

Keywords Supply chain collaboration · Maturity model · Performance $\cdot$ Operations management $\cdot$ Information integration

\section{Introduction}

In the 1980s and 1990s, Wal-Mart and Proctor \& Gamble inspired companies with their successful story of reducing cost by joining in trading relations that consider exchanging information as the key component [1]. Since then, collaboration in the context of supply chain management has been promoted strongly by both scholars and practitioners [2]. Today, collaboration is one of the most talked about topics in the business world [3] and has become a major challenge for managers in industrial companies [4].

Collaboration in the supply chain is considered as a competitive tool used to improve the business performance [3]; and scholars have affirmed a strong link between SCC and performance levels [5]. Therefore, achieving a greater collaboration level to achieve better performance outcomes is the ultimate goal of all firms [6]. In fact, many attempts have fallen short of the participants' expectations and have ended in failure [2]. One survey revealed that only $35 \%$ of collaboration initiatives are even moderately successful [7]. The success rate of collaboration initiatives has been less than expected $[8,9]$.

Yet our knowledge is relatively weak about the connections between collaboration, resulting performance and how it leads to the greatest overall performance improvements [10]. How exactly different maturity levels of

Thi Ho, phuongdung2512@gmail.com; Arun Kumar, a.kumar@rmit.edu.au; Nirajan Shiwakoti, nirajan.shiwakoti@rmit.edu.au|'School of Engineering, RMIT University, Melbourne, Australia. 
collaboration lead to different levels of performance is not well understood and has not been adequately addressed in literature $[5,11]$. This kind of link is mentioned to be still in its early stage [12] with a lack of evidence of extensive implementation [13]. The literature is still searching for the relationship between maturity level and performance in a supply chain context $[14,15]$. Furthermore, it is highlighted that the relationship between collaboration and performance was examined mainly on a quantitative basis with the majority of papers to test the hypothesis [16]. There are calls for further empirical research on this link [17]. Especially, there is a need for qualitative based research such as in-depth case studies to increase our understanding of SCC and performance in the real-world [16]. Furthermore, since the relationship between SCC and performance is mentioned to be almost universally accepted without much proof with a few papers based on primary data and empirical studies [16].

As regards to the industry type, since it is affirmed as a control variable correlated with supply chain performance and practices [18], more insights for best practices of industry-specific bias would be very beneficial to minimize the chance of failure of implementation phase [6]. Cao and Zhang [6] mentions this lack in the current body of knowledge. In-depth research in specific industry will help industrial managers to have the strategic decisions of key actions to perform for their organizations.

Given these limitations, this study aims at developing a more in-depth research at exploring the relationship between collaboration maturity levels and performance in a specific industry. Through a maturity model for SCC (MM-SCC) which have been developed in previous study, SCC practices are evaluated, and the current maturity level is measured. The effects on the performance are quantitatively and qualitatively measured with actual data of key performance indicators (KPIs) and subjective evaluation of managers to reconfirm and explain more for the effects. This also fills the gap of quantitative-based research measuring the effects with real data in the existing body of knowledge [16]. Case studies are chosen to address the research aim.

The selected context is textile and apparel industry with the following reasons. Among industry types, the textile-apparel industry is recognized as one of the longest, most fragmented and inflexible supply chains in the world $[19,20]$. With characteristics of short product life cycle, high demand uncertainty and high volatility $[14,15$, $21]$ it is necessary for textile-apparel industry to have a responsive and efficient supply chain [20,22]. This responsiveness and efficiency characteristic are affirmed to be affected by the effectiveness in communicating [23] and by the level of collaboration among partners in the chain
[24]. This selection is due to the significance of high collaboration level to the success of the chain $[20,22]$.

Since the textiles and clothing industry is mentioned to be a major part of manufacturing and trade as well as the gate of choice to step into industrialization in most developing countries [25]. A developing country is chosen as a case study in this research. Among the leading countries in this industry, Vietnam is recognized as one of the countries with lowest added value in the apparel value chain [26]. Moreover, Vietnamese chain has witnessed a decreasing trend in value added in manufacturing during recent years with high unit cost [27]. The implications of this research can be common factors for the development of the textile and apparel sector in scores of Vietnam specifically and of developing countries in general. Having a clear picture of MM-SCC and textile-apparel context is helpful in improving the awareness of contributions of this study to the body of knowledge.

The research is structured as follows. The second section provides a theoretical background for SCC, the maturity model, and MM-SCC. This is followed by the methodology adopted for this research and a description of data collection. The fourth section presents the results. The next section illustrates the discussion and managerial implications. There ends with contribution and future research.

\section{Theoretical background and model development}

This study is conducted based on applying proposed model MM-SCC in a particular industry. This section presents a review of the literature pertinent to the aim of developing the model. The literature review has been sorted according to three distinct categories. The first category broadly outlines the concepts of SCC and the second category highlights the maturity model. The latter category illustrates the developed model in SCC field.

\subsection{Supply chain collaboration}

SCC is defined as the inter-organisational processes among and between members of a supply chain $[2,6$, 28-31], which aims to create a seamless and synchronised supply chain that leads to increased responsiveness and performance to satisfy customers $[28,30]$. These activities are based on mutual goals and trust, along with shared risk and reward $[2,6,8,29,31]$.

Researchers use the word "collaboration" to express the context of their research loosely [31]. In the context of supply chain, collaboration is complemented by other terms such as "integration" [3, 32], "cooperation" [33] or "coordination" [34]. Some authors refer collaboration as 
inter-firm cooperation, integration or coordination and often use them interchangeably based on the main goal to achieve effective and efficient flows of products and services, information, money and decisions, to provide maximum value to the customer [35]. However, in some research, collaboration includes a spectrum of relationship types. These different relationships in supply chain follow movement paths, such as Open market negotiations-Cooperation-Coordination-Collaboration [36]; Communicator-Coordinators-Cooperators-Collaborators [28] or Communication-Coordination-Intensive collaboration-Partnerships [7]. There is no consistency of the definition as well as the position of collaboration, integration, coordination and cooperation in a supply chain among scholars. As such, in this study, the researchers consider these terms as the phenomenon of inter-organisational processes among and between members of a supply chain based on mutual goals, mutual trust, shared risk and shared reward rather than the definition of "closeness" or "together" level in one relationship.

\subsection{Maturity model}

The word "maturity" is used here to denote the quality concept developed by Crosby [37]. The earliest model of Quality Management Maturity Grid evaluated the status and evolution of a firm to quality management [37, 38].

Maturity model is defined as a matrix of practices which is considered as a development path or an improvement tool for organizations [39]. Maturity models have been adopted in many management research fields, including process management and performance management [5] with a variety of application domains, including supply chain management and collaboration process [40].

Maturity model is simply referred to capability maturity model (CMM)/capability maturity model integration (CMMI) by many investigators [39]. CMMI is a process maturity framework with a set of key processes [41] guiding organizations toward a more disciplined and higher maturity level [42]. Table 1 summarises the CMMI model according to the characteristics of each maturity level [43].
To reach a particular level, an organization must satisfy all of the goals of the process area or set of process areas that are targeted for that level.

Evidence has shown that maturity models are applied in a variety of domains, however, maturity models for processes in the field of supply chain and collaboration is currently not well-understood $[5,40]$. Given this limitation, the authors have developed a maturity model for supply chain collaboration (MM-SCC) based on CMMI approach [15]. This model is considered as a guidance for organisations in implementing SCC processes sequentially through stages. This is also a diagnostic tool for organisations to evaluate the current practices and to improve to a higher level.

\subsection{MM-SCC}

As mentioned in the definition, SCC is a set of process requirements. To build the model, a literature review on these processes has been done by the authors, including prerequisite processes as antecedents; key activities; and sustaining and improvement activities [44]. The model was further developed from our previous work, based on CMMI approach.

The summary of model is provided in Table 2, including two main parts: maturity levels and process requirements.

Each process involves the activities (sub-process). These sub-processes will give a detailed instruction for implementing the main processes. More details of subprocesses of each process requirement are illustrated in "Appendix 1".

This study is the very first application of this model in real environment to explore in-depth the SCC phenomenon.

\section{Methodology}

The section presents the strategy to address the research problems with the constitution of the research methods for data collection and analysis. This is a mixed-method

Table 1 CMMI model. Source: [43]

\begin{tabular}{|c|c|}
\hline Maturity level & Characteristics \\
\hline 1. Initial & Processes are ad-hoc and chaotic \\
\hline 2. Managed & Processes are planned, performed, measured, and controlled according to documented plans \\
\hline 3. Defined & Processes are well characterized and understood, and are described in standards, procedures, tools, and methods \\
\hline $\begin{array}{l}\text { 4. Quantitatively man- } \\
\text { aged }\end{array}$ & Processes are controlled using statistical and quantitative techniques \\
\hline 5. Optimising & $\begin{array}{l}\text { Processes are continually improved based on a quantitative understanding of the common causes of variation } \\
\text { inherent in processes }\end{array}$ \\
\hline
\end{tabular}


Table 2 MM-SCC model. Source: [15]

\begin{tabular}{|c|c|c|}
\hline Level & Characteristics & Collaboration process requirement \\
\hline 1. Initial & $\begin{array}{l}\text { Collaborative supply chain processes are usually ad hoc and chaotic. } \\
\text { The organization usually does not provide a stable environment for } \\
\text { processes to perform. Success in collaboration process may happen, but } \\
\text { it is still dependent on individual initiative and skills, not on the use of } \\
\text { proven processes, and organizations are not able to repeat their past } \\
\text { successes }\end{array}$ & $\mathrm{N} / \mathrm{A}$ \\
\hline 2. Managed & $\begin{array}{l}\text { SCC in organizations starts to be modified towards basic activities. Collab- } \\
\text { oration processes are planned with requirements and involved activities. } \\
\text { Commitments are established among relevant stakeholders. Collabo- } \\
\text { ration processes are performed and controlled to meet requirements } \\
\text { according to documented plans but mostly reactive and repeatable }\end{array}$ & $\begin{array}{l}\text { Antecedents } \\
\text { 1. Managerial commitment and strategic intent } \\
\text { 2. Resource investment and development } \\
\text { 3. Free information flow and system integration } \\
\text { 4. Relationship building and management } \\
\text { 5. Formalisation } \\
\text { 6. Rationalisation }\end{array}$ \\
\hline 3. Defined & $\begin{array}{l}\text { SCC processes are well characterized, understood and described through } \\
\text { a greater attention to documentation, standardization, procedures, } \\
\text { tools, and methods. Standard collaboration processes are managed pro- } \\
\text { actively and consistently spread to different areas of the organization. } \\
\text { Process objectives are established and ensured to appropriately address }\end{array}$ & $\begin{array}{l}\text { Key activities } \\
\text { 1. Information sharing } \\
\text { 2. Goal congruence } \\
\text { 3. Decision synchronisation } \\
\text { 4. Incentive alignment } \\
\text { 5. Resource sharing } \\
\text { 6. Collaborative communication } \\
\text { 7. Joint knowledge creation }\end{array}$ \\
\hline $\begin{array}{l}\text { 4. Quanti- } \\
\text { tatively } \\
\text { managed }\end{array}$ & $\begin{array}{l}\text { Collaboration processes are quantitatively managed in accordance with } \\
\text { agreed-upon metrics. Detailed measures of supply chain performance } \\
\text { are collected and statistically analyzed. Special causes of collabora- } \\
\text { tion process variation are identified and corrected to prevent future } \\
\text { occurrences. Collaboration process happens at a strategic level where } \\
\text { integrated and coordinated strategies aim at achieving the overall sup- } \\
\text { ply chain performance between multiple parties }\end{array}$ & $\begin{array}{l}\text { Sustaining and improvement activities } \\
\text { 1. Performance measurement }\end{array}$ \\
\hline 5. Optimising & $\begin{array}{l}\text { Common causes of process variation are addressed, identified, evalu- } \\
\text { ated, and deployed. Collaboration process performance is continually } \\
\text { improved through both incremental and innovative technological } \\
\text { improvement towards the common objectives of supply chain. The } \\
\text { interaction is truly through all chain organizations and collaboration } \\
\text { happens to achieve the maximum supply chain effectiveness }\end{array}$ & $\begin{array}{l}\text { Sustaining and improvement activities } \\
\text { 1. Continuous improvement }\end{array}$ \\
\hline
\end{tabular}

study including two phases: model content validity and case studies. The subsequent sections are the results expanding upon this research design.

\subsection{Phase 1: model content validity}

In this study, the model is validated before its application. The content validity check is based not only on the information available in the relevant literature, but is also checked in consultation with a panel of practitioners and academic experts with substantial knowledge about the topic and the context $[2,45-47]$. Semi-interview method with questionnaire tool is used to ask for the experts' agreement level on the model. The result is quantitatively analyzed through content validity ratio (CVR) to decide the appropriateness of model's content [45].

\subsubsection{Expert selection}

In the supply chain field, title of experts who participated in the survey relating to SCC aspect is shown in Table 3.

Table 3 Expert positions

\begin{tabular}{ll}
\hline Experts & Positions \\
\hline Practitioners & Executive positions: \\
& CEO/President/Vice \\
president/Director [3, \\
$6,48]$ \\
Manager/executive/ \\
senior staff in: \\
Supply chain/logistics \\
{$[3,30,45,49-51]$} \\
Sales [45, 49] \\
Purchasing [30, 45, 49] \\
IT [50] \\
Manufacturing/produc- \\
tion [49, 50] \\
Professor/Lecturer [2] \\
\hline
\end{tabular}




\subsubsection{Method and tool}

A semi-structured interview with questionnaire which incorporated the MM-SCC model is used to ask for the experts' agreement with regards the model. Two kinds of questions were used, close-ended and open-ended questions.

- For close-ended questions, a five-point Likert scale is used to allow respondents to indicate the extent to which they agreed or disagreed with the model. For open-ended questions, the respondents are asked to give their opinions on the model. If a process of item needed to be added, the survey will be conducted again.

- For close-ended questions, data are statistically analysed to confirm the validity of measurement using the content validity ratio (CVR) as a content validity index in rejection or retention of specific items [52]. CVR is calculated for each level, process requirement and subprocess requirements. CVR is a direct linear transformation from the percentage saying "agree and strongly agree". This ratio has to meet the minimum required CVR to be not eliminated [52].

$\mathrm{CVR}=\frac{n_{e-N / 2}}{N / 2}$

$\mathrm{n}_{\mathrm{e}}=$ number of experts indicating agree and strongly agree, $\mathrm{N}=$ total number of experts.

\subsection{Phase 2: case study}

The model is then applied in case studies to evaluate the current practices and measure the SCC level. These outcomes of practices and levels are used along with performance outcomes to evaluate and analyze the relationship between SCC and performance. The effects of SCC on performance are quantitatively assessed through real data of $\mathrm{KPIs}$ and subjectively evaluated by managers as well.

\subsubsection{Number of cases}

As this is the first application of the model, the selection of multiple cases is needed to assure the robustness of the model by replicating the finding. In addition, due to the benchmark function of the model, multiple-case design can provide the comparisons of how SCC affects performance among the contexts. In this study, two cases varying in scale and culture are chosen due to following reasons. Since the function of the model is to diagnose the current practices and problems to make the improvements, the application of the model requires an in-depth research with many activities involving different functions, departments and respondents. Multiple sources of evidence need to be collected to ensure both the reliability and construct validity for the evaluation. As such, it is not a small case study at each case. In addition, relationships in a supply chain is mentioned to be varying from tier to tier [53]; in one organization under the same maturity level, the relationship with different partners may vary from partner to partner. Multiple unit of analysis in one case is chosen to explore the phenomenon in-depth.

The embedded, multiple-case (multiple contexts, multiple units of analysis) type with two cases is suitable for the research purpose by covering the multiple-case design and providing sufficient resources for in-depth research at each case.

\subsubsection{Model application}

To assess the current maturity levels, the respondents answer whether or not the organisation performs and meets the process requirements in the MM-SCC model. If the answer was "yes", evidence had to be provided to support the affirmative answer. Data collection for this study utilizes multiple sources of evidence, including on-site interviews, observations and documentary. While the onsite interviews and observations are qualitative in nature, documentary evidence was collected for each answer "yes". If one answer was negative, this meant this maturity level was not met [54]. The enterprise will receive the classification of the last maturity level completed. From this maturity classification, the enterprise will establish improvement plan to achieve the target. This classification allows the enterprise to define an improvement roadmap.

\subsubsection{Case information}

Two garment companies were chosen. Real names were redacted for privacy purpose. This research has obtained the Ethics approval from College Human Ethics Advisory Network (CHEAN), College of Science, Engineering and Health, RMIT University (ID: SEHAPP 61-16) to conduct the interviews and collect data at two textile apparel companies in Vietnam (including consent form of invitation to participate in the research project and approval letters from two companies).

In the Vietnam context, customers appoint the suppliers for the manufacturers; as such this industry tends to be dominated by customer relationship. This research focuses on the evaluation of the downstream relationship between garment manufacturers and customers.

Summary of case information is presented in Table 4. 
Table 4 Case information

\begin{tabular}{lll}
\hline & ABC company & XYZ company \\
\hline Type & Joint Stock Company & Limited Liability Company \\
& 100\% of capital from Vietnam & $100 \%$ of capital from a Hong Kong group \\
& Over 40 years & Over 10 years \\
Position & One of the leaders in the Vietnamese garment industry & One of the ten largest export garment businesses \\
Revenue & An export sale: US\$651 million (2015) & Revenue: US\$720 million (2015) \\
Product & Suits, shirts, trousers & Sweaters and T-shirts \\
Customer & International customer: more than 50 international brands & Mainly 8 famous international brands from US and Japan \\
& Domestics customer: Under its own house brand's designs & \\
Production modality & Cut-Make-Trim (CMT) -main customers ${ }^{\mathrm{a}}$ & FOB \\
& Free-On-Board (FOB) & \\
& Original-Brand-Manufacturing (OBM $)^{\mathrm{c}}$ & \\
\hline
\end{tabular}

${ }^{a}$ Materials are provided by customers. Enterprises simply perform the manufacturing and assembling function

${ }^{b}$ Enterprises offers customers their own materials or outsource materials from the nominated suppliers

'Products are designed, manufactured, and retailed under own house brands

\subsubsection{KPI selections}

Following that step, the authors then explore how different maturity levels affect performance outcomes. Due to the nature of the CMT and FOB method, Vietnam's apparel enterprises only perform outsourcing contracts and the customers provide firms with all design as well as transportation arrangements [55]. Therefore, upgrading quality and on-time delivery become more transparent in cultivating importers' confidence in Vietnamese products [55]. The literature also indicates that quality and delivery schedule are common concerns for both customers and manufacturers [56]. Additionally, because CMT is the simplest production practice-only requiring manufacturing capacity and a little designing capacity for making counter-samples-Vietnamese manufacturers target their efforts at strengthening their operational capacity [55]. Therefore, capacity utilisation (the ratio of the actual output over the target output) is also considered in this study. Overall, data related to quality level, on-time delivery and capacity utilisation are collected to assess the efficiency of the system.

\section{Results}

This section presents the findings of the model application which is the expansion of the work of research design at Sect. 3. Starting with the results of content validity, the latter part of this section is the results of model application including measured SCC maturity level at each case, and performance outcomes with the results of KPIs. This section establishes the setting that forms the basis of the analysis in the subsequent Sect. 5 .

\subsection{Model content validity}

The pilot was done to identify format, ambiguous items, the quality of worded questions and instructions for the model. Pretesting and piloting is conducted. Following piloting, the final version of the questionnaire is prepared to go on to be tested for the content validity in a largescale survey.

The respondents were contacted via telephone and email to request for participating in the interview. There were 25 experts agreeing to participate in the research; however, the interviews were only able to be conducted with only 20 experts in 2 months (June 2016-August 2016). While most of the industrial practitioners were managers and senior staff with an average of 5 years' experience, the academic experts had more than 5 years of experience. The job title and job function of participants vary from field to field relating to SCC. The senior staff and manager occupy most of job title and these respondents are working at different fields relating to SCC.

In this study, because there were 20 participants, the minimum value of CVR of each component was 0.42 [52]. The result showed that all the experts agreed with the level definitions and process requirements of each level (CVR value greater than 0.42). However, there were seven sub-processes with the CVR below 0.42 , which were considered as not suitable for considering the relationship between manufacturers and customers in the Vietnam textile and apparel industry context. The seven eliminated sub-processes are also shown in "Appendix 1" with the sign "**" for clarity. These eliminations were explained during the interview and consistent with the analysis of the Vietnamese context background of manufacturing and outsourcing contracts for international customers. After 
eliminating seven sub-processes, the final MM-SCC model was built for the Vietnamese textile and apparel industry.

\subsection{Case application}

\subsubsection{Collaboration maturity level}

Prior to each interview, the respondents are informed regarding the purpose of the study and the model is explained. Because there is no rank or title of supply chain manager at both companies, the research is conducted at different departments of the company. Executives, managers or senior staffs of departments of sales, information system and enterprise resource planning (ERP), production, logistics and inventory, industrial (lean) engineering (IE) are interviewed based on the model. The respondents answer for the relevant fields. If the answer is different for the same process requirement, the disagreements are handled by follow-up another interview with more explanation and more documentary evidence provided. For "yes" answer, the evidence is provided, including documents, photos (posters), data and observations. Data collection for this study utilized multiple sources of evidence, including on-site interviews, observations and documentary to ensure both the reliability and construct validity for the study $[57,58]$.
The summary of model application is presented in Table 5. The detailed explanation along with evidence are given in "Appendix 2".

$A B C$ Company cannot meet all the process requirements of level 2 (there is "NO" answer at level 2); hence it is on level 1 in the scale. If the company cannot meet all the process requirements of a particular level, it cannot be on that level [54]. On the other hand, XYZ Company has performed and met all the process requirements of up to level 4; therefore, it has reached to the level 4 of the model. Each case performs a specific collaboration maturity level gauged by the MM-SCC model.

\subsubsection{Performance}

The KPIs of quality level, on-time-delivery and utilization are collected (Table 6). For XYZ Company, since it has built a very an effective performance measurement system, monthly KPIs reports of Production Department (quality level and utilisation) and Sale Department (on time delivery) are used for KPIs. For ABC Company, there is no KPIs report. Only raw data are recorded daily. The researcher collected the relevant data and analysed for the KPIs. The report of number of defects, the target quantity and actual quantity are used to analyse the quality level and utilization. On-time delivery is tracked based on the delivery

Table 5 Model results

\begin{tabular}{|c|c|c|}
\hline Process requirements & ABC company & XYZ company \\
\hline Level 1 & $\mathrm{~N} / \mathrm{A}$ & \\
\hline \multicolumn{3}{|l|}{ Level 2} \\
\hline Managerial commitment and Strategic intent & Answer: Yes & Answer: Yes \\
\hline Resource investment and development & Answer: Yes & Answer: Yes \\
\hline Rationalisation & Answer: Yes & Answer: Yes \\
\hline Internal alignment & Answer: No & Answer: Yes \\
\hline Relationship and trust building & Answer: No & Answer: Yes \\
\hline Information Flow and System Integration & Answer: No & Answer: Yes \\
\hline Formalisation & Answer: No & Answer: Yes \\
\hline \multicolumn{3}{|l|}{ Level 3} \\
\hline Goal congruence & Answer: Yes & Answer: Yes \\
\hline Decision synchronisation & Answer: Yes & Answer: Yes \\
\hline Incentive alignment & Answer: Yes & Answer: Yes \\
\hline Resource sharing & Answer: Yes & Answer: Yes \\
\hline Joint knowledge creation & Answer: Yes & Answer: Yes \\
\hline Collaborative communication & Answer: No & Answer: Yes \\
\hline Information sharing & Answer: No & Answer: Yes \\
\hline \multicolumn{3}{|l|}{ Level 4} \\
\hline Performance measurement & Answer: No & Answer: Yes \\
\hline \multicolumn{3}{|l|}{ Level 5} \\
\hline Continuous improvement & Answer: No & Answer: No \\
\hline SCC maturity level & Level 1 & Level 4 \\
\hline
\end{tabular}


Table 6 KPls

\begin{tabular}{|c|c|c|c|c|c|c|c|c|c|c|}
\hline \multirow{3}{*}{$\begin{array}{l}\text { Company } \\
\text { Customer } \\
\text { Product }\end{array}$} & \multicolumn{5}{|l|}{$A B C$} & \multicolumn{5}{|l|}{$X Y Z$} \\
\hline & \multicolumn{2}{|l|}{ CMT } & \multirow{2}{*}{$\begin{array}{l}\text { FOB } \\
\text { Vest }\end{array}$} & \multirow{2}{*}{$\begin{array}{l}\text { OBM } \\
\text { Shirt }\end{array}$} & \multirow[t]{2}{*}{ Average } & \multirow{2}{*}{$\begin{array}{l}\text { US } \\
\text { T-shirt }\end{array}$} & \multirow[t]{2}{*}{ Japan } & \multirow{2}{*}{$\begin{array}{l}\text { US } \\
\text { Sweate }\end{array}$} & \multirow{2}{*}{$\begin{array}{l}\text { Japan } \\
\text { er }\end{array}$} & \multirow[t]{2}{*}{ Average } \\
\hline & Vest & Shirt & & & & & & & & \\
\hline $\begin{array}{l}\text { Quality level \% } \\
\text { (final product) }\end{array}$ & 94.18 & 78.62 & 88.32 & 83.58 & 86.18 & 98.2 & 99.81 & 97.95 & 97.56 & 98.38 \\
\hline On-time delivery $\%$ & 78 & 74 & 70 & 85 & 76.75 & 99.40 & 99.5 & 96 & 98 & 98.225 \\
\hline Utilisation \% & 83.4 & 82.23 & 83.4 & 82.23 & 82.82 & 103.52 & 103.75 & 99.20 & 108.62 & 103.77 \\
\hline
\end{tabular}

The tolerance of provided material is $+10 \%$ and $X Y Z$ makes use of all the materials. The overproduced quantity is negotiated with the customer for a special price

date and completed date for each order. Raw data can only be tracked back for 1 year.

\section{Discussion}

This section is to analyze the relationship between SCC and performance based on the results of model application. The effects of SCC on performance are evaluated quantitatively through KPIs and qualitatively through subjective assessment from managers to reconfirm and explain more for the effects. Furthermore, how internal and external relationship interact is also pointed out. Finally, the conclusion along with managerial implications is provided at the end.

\subsection{SCC maturity level and performance}

The quality level of $A B C$ is low, lying within two-sigma with $86.18 \%$ compared to $X Y Z$ 's quality level, which lies within three-sigma with $98.38 \%$. The on-time-delivery percentage is certainly an important metric for customers; $A B C$ Company's late delivery percentage is high with $23.25 \%$ compared to only $1.77 \%$ for XYZ Company. Further, the utilisation of $A B C$ is much lower than 1 or $100 \%$ on the percentage scale, while XYZ's is always greater than 1 . This proves that $A B C$ Company's resource utilisation is inefficient. The poor-quality cost of high defects and airship cost will definitely raise the manufacturing cost for $A B C$ Company. This will also result in $A B C$ jeopardising their long-term relationship with customers.

Comparing between $\mathrm{ABC}$ and $\mathrm{XYZ}$ Company, it displays that a lower level of collaboration maturity level results in a lower performance level in their relationships. The positive outcomes of SCC have been declared with the majority of previous studies agreeing on the direct positive link between SCC and performance [59]. The results of the comparison between $\mathrm{ABC}$ and $\mathrm{XYZ}$ Company are consistent with the literature. We were able to build on the previous literature that the effects on the performance are quantitatively and qualitatively measured through actual data of key performance indicators (KPIs).

\subsection{Internal collaboration and performance}

The differences in process requirements between two companies are analysed to explore the SCC phenomenon. Obviously, both companies meet the process requirements of managerial commitment and strategic intent, resource investment and development, rationalisation, goal congruence, decision synchronisation, incentive alignment, resource sharing and joint knowledge creation. It can be seen that these are intra-organizational processes to fulfil its customers' requirements. For a customer-driven commodity chain; customers' satisfaction is vital to the survival of an organisation and the core strategy of any organization. As such, it is incredibly important to ensure an effective external collaboration by working closely with customers and meet their requirements. All the organizations are pursuing customer relevant activities such as customer services.

The differences in SCC practices between two companies are presented in these process requirements-internal alignment, relationship and trust building, information flow and system integration, formalisation, information sharing, collaborative communication, and performance measurement. These are inter-organizational processes which are across functions in one organisation. This internal collaboration is usually considered under two dimensions - the integration of physical and information flows which is labelled as information integration and coordination of operational decisions [60]. Consistently with this classification, the observed differences between the two companies are information integration (information flow and system integration, information sharing or collaborative communication) with the application of ERP software and operations management (internal alignment) with managerial approach using lean manufacturing. The lack of intra-organizational integration is mentioned to be the cause preventing manufacturers to achieve the benefits of external integration and from fully impacting performance 
$[35,61-64]$. In other words, internal failure is a major barrier to SCC [65]. Literature has also shown that information integration [66-68] and operations management [69-72] have a direct and positive impact on performance. Successful collaboration requires effective internal alignment first, which is a key element for enterprises to engage with before extending the scope of integration outside [73].

Inevitably, since ABC Company does not meet the process requirements at level 2 that are antecedents for SCC, the process requirements at level 3 and 4 cannot be performed either. $A B C$ has showed that it only focused on the inter-organizational processes and was having the problem with intra-organizational processes. The fact is that while focusing on the "appearance", $A B C$ fails to maximize the quality of their internals. The effects of internal collaboration with information integration and operations management on performance are also subjectively evaluated by managers such as:

"We have many wastes in production system such as high (WIP), high quality defects. The manufacturing system has many problems with very low-quality level, on-time-delivery and effectiveness compared to other companies in the industry."-ABC Production manager.

\begin{abstract}
"The rescheduling manufacturing is not timely made because the actual vs planned quantity is recorded at the end of day and sorted out the following day. Inventory system is not able to link with production system; hence, the materials are sometimes supplied to the plant and cause a lot of work-in-process (WIP)."-ABC Production manager.
\end{abstract}

\subsection{Internal collaboration and external collaboration}

Research shows that while most of the authors agree that internal integration is positively associated with operational and business performance of the manufacturer in a direct or indirect way, while external integration have been claimed to probably have the reverse impacts or no direct association with performance $[12,35,74]$. Additionally, it is pointed out that there is still a lack of research exploring how internal and external relationship interact $[35,75]$. The link between them results being somewhat divergent [16].

To have an in-depth exploration on this, the within case analysis is conducted to examine the relationship among different customers in one case. To consider the external relationship with customer, the degree of involvement, influence in the company's decision and level of strategic partnership with suppliers or follow-up with customers for feedback are evaluated by managers [76]. These are based on the nature of production modality, and customers' culture and policy. The results are summarized in Table 7.

In ABC Company, under the same product categoryeither vest or shirt, it can be seen from Table 6 that a higher level of external integration causes a negative effect on performances in both terms of quality level and on time delivery. For example, in the category of vest product, quality level and on-time-delivery of CMT Customer are $94.18 \%$ and $78 \%$ respectively, higher than $88.32 \%$ and $70 \%$ of FOB Customer even FOB Customer has a better relationship with the manufacturer. The phenomenon is similar under the shirt category between OBM and CMT. Here, two variables of external integration and performance have a negative association.

In contrast to previous case, in XYZ Company, it is seen that the customer with higher integration can create higher effectiveness for the operational system as demonstrated through the performance indicators in all aspects. Specifically, in either T-shirt or sweater category, Japanese customer with higher integration level can create a higher quality level in general, on time delivery and efficiency for the manufacturer (the surveyed period is noted with the change of workers in production line for Japanese customers; hence it created more defects than usual).

So, whether external integration is effective in enhancing firm performance or not. The reason of this inconsistency is provided by managers.

"The more involvement the customers have, the more defective items are identified. We are not capable enough to meet it at the first time. We must rework and solve and this leads to the low quality level and low on time delivery percentage."-ABC Lean manager.

When the requirements are high, the company is not capable of handling those requirements and so it fails to meet the requirements. The lack of internal capability causes the adverse effect of external integration on performance. The XYZ Company, on the other hand, is at a high level of internal integration; so, the more integrated the company is with the customer, the higher the performance

Table 7 Customers' external collaboration

\begin{tabular}{|c|c|c|c|c|c|}
\hline \multirow{2}{*}{$\begin{array}{l}\text { Company } \\
\text { Customer type }\end{array}$} & \multicolumn{3}{|l|}{$A B C$} & \multicolumn{2}{|l|}{$\mathrm{XYZ}$} \\
\hline & OBM & CMT & FOB & US & Japan \\
\hline Customer's influence & Low & Medium & High & Medium & High \\
\hline Customer involvement & Low & Medium & High & Medium & High \\
\hline Feedback follow-up & Low & Medium & High & Medium & High \\
\hline $\begin{array}{l}\text { External collaboration } \\
\text { level }\end{array}$ & Low & Medium & High & Medium & High \\
\hline
\end{tabular}


is. This positive correlation is explained by managers as below:

"Japanese customer has a very long-term relationship with us through long-term contracts, so we can build a standard and stable production system. While the US customers do not have regular orders and the product type is very different, so we must re-setup the system for different orders. This leads to the lower efficiency and effectiveness".-XYZ Production manager.

The relationship between internal and external is mentioned in the literature that internal integration is regarded as the prerequisite for outside collaboration among trading partners in other findings $[73,77]$. Internal integration positively generates external integration [78] or critical enablers/vital link facilitating the relationship between customer integration and supplier integration [35, 79]. Serving as a foundation of the external integration [73, $74,77,80]$, internal integration also has a moderating effect on the relationship of external integration and performance $[12,35,74,78,79]$.

Consistent with literature, the results show that, with a good internal capability, XYZ is able to meet the customers' requirements. Therefore, the effective integration will enhance the stability and robustness for the system and link to performance. From the within-case analysis, these observations demonstrate the moderating role of internal integration in the relationship between external integration and the performance. If a system is well-integrated, the higher level of integration with customer will lead to higher performance. It is clearly seen from within-case of $A B C$ Company, due to the lack of internal integration, even the higher level of external integration cannot bring higher performance for the company. XYZ Company has built an effective system; hence, it is able to pursue successful external collaboration with customers.

\subsection{Managerial implications}

The application of the model has shown that ABC Company, while focusing on the "appearance", failed to meet the requirements of their internal. The results of this inefficiency are clearly indicated by ABC's KPIs. The key for managers is to understand that organizations should begin SCC with internal integration to build the foundation for customer and supplier integration $[35,62,81]$. It is also mentioned that a firm with customer-driven business should undertake work of integrating the firm internally to reap the fullest rewards [61]. Irrespective of how much effort a firm spends to find new customer or maintain a relationship, the research indicates that failure in internal integration is sufficient enough to cause the failures in
SCC. Capabilities of both internal and external integration are mentioned to be crucial to achieve better performance [81]. However, this is a common problem in the industry as is stated in the literature that many companies tend to only pursue external collaboration and often pay less attention to internal capability [82, 83].

These problems are rooted with the inefficiency in information integration and managerial approach. A lack of a fully implemented, effective information integration and management capability prevents companies from achieving a collaboration maturity level. In addition, this inefficiency also results in low performance measures. Firms should move effort toward increasing levels of communication and cross-functional activities $[62,84]$.

Along with managerial approaches, namely lean manufacturing, information systems, ERP in particular, provides the information and decision support to the management are also developed [85]. These have also received attentions from managers for operational excellence during the last decade [86]. Based on the fact that ABC Company has developed ERP and lean manufacturing activities, improvement scenarios for $A B C$ Company are suggested with improvement activities for current systems which identify problems and propose solutions with a smallscale tuning of a system rather than developing a new approach.

Although MM-SCC serves the function of the benchmark rating method to compare the organization's capability to itself over time, in this study, these improvement activities have not been practically be applied for case study to examine the effects of these future scenarios on the performance. As such, longitudinal case studies considering how conditions change at different points in time after applying improvement activities with real data will contribute significantly to the existing body of knowledge. To serve this purpose, simulation approach is suggested to foresee the future scenarios.

\section{Contributions and future direction}

This study is a novel contribution that fills the gap of maturity models for effective use in the supply chain context $[11,14]$, particularly in SCC. The proposed model is a SCC process maturity model. The industry can use it as a guideline or a diagnostic tool to compare the organization's capability to others' and itself over time. By applying the model as a form of self-assessment, the enterprises can diagnose the current SCC practices of what have been done and what are missing. Once the root of the problems is found, improvement activities can be acknowledged to improve immature processes to a higher level. 
This is the first application and validation of the MMSCC model based on the data from the Vietnam textile and garment industry. The findings show the applicability and usefulness of MM-SCC. By applying the model, the managers can acknowledge the significance of information integration and operations management capability in order to achieve a higher level of collaboration maturity. This knowledge will enable managers to make strategic decisions to produce a better SCC for their organisation.

Secondly, this study contributes to the lack of empirical researches investigating the mechanisms of SCC and their effects on performance $[21,87]$, especially qualitativebased research such as in-depth case studies to enhance the understanding for this phenomenon in the real world. How higher levels of maturity lead to higher levels of performance is explored.

Thirdly, the study also fulfilled the need of the real data of the performance outcomes in examining the effects of SCC. The study provides evidence-based findings for the relationship between SCC and performance outcomes. Furthermore, industry-based research is conducted to contribute to the lack of how collaboration is adapted to particular needs [6].

MM-SCC model is still in its initial stage of development and there is further need to consider. Firstly, since the MM-SCC model is developed based on the findings from an extensive literature review on the topic of SCC; the developed model should be applicable to other industries. However, as each industry has its own unique characteristics, the content validity is necessary before the model is applied in a specific context. This step will ascertain whether there are other factors that are crucial in the selection or application of the model.

Secondly, while the CMMI model supports two improvement paths using capability levels (for an individual process area) and maturity levels (for a set of related processes), the MM-SCC was only built to support the organisation with the maturity levels. This study did not consider the capability level of each individual process, but rather focussed on meeting a group of process requirements for SCC. Therefore, in future efforts need to be made towards completing the MM-SCC model by developing the capability level for individual process.

Last but not least, the present study is unable to analyse performance for a period of time. This study collected only a year performance data. This limitation is also mentioned in literature to explore the relationship using a longitudinal data. Hence, longitudinal study will be a promising area.

\section{Compliance with ethical standards}

Conflict of interest On behalf of all authors, the corresponding author states that there is no conflict of interest.

\section{Appendix 1: Sub-process}

\begin{tabular}{lll}
\hline Level & Process & Sub-process \\
\hline 2 & $\begin{array}{c}\text { Managerial commitment } \\
\text { and strategic intent }\end{array}$ & $\begin{array}{l}\text { Establish clear strategic intent [3] } \\
\text { Obtain commitment from chief executive and support from senior functional management [30] } \\
\text { Make the recognition of the need for collaboration widespread and visible through the organiza- } \\
\text { tion [30] }\end{array}$ \\
& Develop a supply chain mapping and role definition [3, 30] \\
& Streamline operations [3] \\
& Select supply chain partners [3] \\
& Invest financial and non-financial resources including time, money, training, technology up-dates, \\
& top management's commitment and other resources [3] \\
Resource investment and & Develop sharing learning mechanisms throughout the organization and the supply chain [30] \\
development & Establish project teams, cross-functional management, and develop cross-experienced managers \\
& [30] \\
& Source: [30]: \\
& Establish a high level of trust within the organization as well as with supply chain partners \\
& Find qualified product suppliers and service providers that are committed to continuous \\
improvement & Define the appropriate type of relationship to establish with specific supply chain members \\
building & Establish a supplier development program via process improvement and product development \\
&
\end{tabular}




\begin{tabular}{|c|c|c|}
\hline Level & Process & Sub-process \\
\hline & $\begin{array}{l}\text { Information flow and } \\
\text { system integration }\end{array}$ & $\begin{array}{l}\text { Source: [30]: } \\
\text { Established information systems capable of sharing real time accurate and relevant information } \\
\text { (connectivity) } \\
\text { Inculcate a willingness to share information across functions and between organizations } \\
\text { Establish a revenue-tracking system } \\
\text { *Improve forecast accuracy throughout the entire supply chain }\end{array}$ \\
\hline & Formalization & $\begin{array}{l}\text { Source: [30]: } \\
\text { Co-developing performance metrics (e.g. key performance index, scorecard, and the resulting } \\
\text { incentive) } \\
\text { Prior agreements on collaboration goals or objectives } \\
\text { Determining roles and responsibilities of each partner as well as reporting } \\
\text { Mechanisms in the relationship } \\
\text { Laying out collaborative implementation plans } \\
\text { Standardizing information technology } \\
\text { Aligning collaboration schedules and } \\
\text { Specifying information to be shared }\end{array}$ \\
\hline & Rationalization & $\begin{array}{l}\text { Source: [30]: } \\
\text { Identify and take advantage of commonalities and collaborative improvement opportunities } \\
\text { Simplify the network—-supply base, customer base, and service provider reduction } \\
\text { Eliminate unnecessary or slow moving SKUs }\end{array}$ \\
\hline \multirow[t]{7}{*}{3} & Information sharing & $\begin{array}{l}\text { Source: [8] } \\
\text { Exchange relevant information } \\
\text { Exchange timely information } \\
\text { Exchange accurate information } \\
\text { Exchange complete information } \\
\text { Exchange confidential information }\end{array}$ \\
\hline & Decision synchronization & $\begin{array}{l}\text { Source: [8] } \\
\text { Jointly plan on promotional events } \\
\text { Jointly develop demand forecasts } \\
\text { Jointly manage inventory } \\
\text { * Jointly plan on product assortment } \\
\text { *Jointly work out solutions }\end{array}$ \\
\hline & Incentive alignment & $\begin{array}{l}\text { Source: [8] } \\
\text { Share costs (e.g. loss on order changes) } \\
\text { Share benefits (e.g. saving on reduced inventory costs) } \\
\text { Share any risks that can occur in the supply chain } \\
\text { Be commensurate with investment and risk }\end{array}$ \\
\hline & Goal congruence & $\begin{array}{l}\text { Source: [8] } \\
\text { Have agreement on the goals of the supply chain } \\
\text { Have agreement on the importance of collaboration across the supply chain } \\
\text { Have agreement on the importance of improvements that benefit the supply chain as a whole } \\
\text { Have agreement on achieving goals through working towards the goals of the supply chain } \\
\text { Jointly layout collaboration implementation plans to achieve the goals of the supply chain }\end{array}$ \\
\hline & Resource sharing & $\begin{array}{l}\text { Source: [8] } \\
\text { Use cross-organizational teams frequently for process design and improvement } \\
\text { Dedicate personnel to manage the collaborative processes } \\
\text { Share technical supports } \\
\text { Share equipment (e.g. computers, networks, machines) } \\
\text { Pool financial and non-financial resources (e.g. time, money, training) }\end{array}$ \\
\hline & $\begin{array}{l}\text { Collaborative communi- } \\
\text { cation }\end{array}$ & $\begin{array}{l}\text { Source: [8] } \\
\text { Have frequent contacts on a regular basis } \\
\text { Have open and two-way communication } \\
\text { Have informal communication } \\
\text { Have many different channels to communicate } \\
\text { Influence each other's decisions through discussion rather than request }\end{array}$ \\
\hline & Joint knowledge creation & $\begin{array}{l}\text { Source: [8] } \\
\text { Jointly search and acquire new and relevant knowledge } \\
\text { Jointly assimilate and apply relevant knowledge } \\
\text { *Jointly identify customer needs } \\
\text { *Jointly discover new or emerging markets } \\
\text { *Jointly learn the intentions and capabilities of our competitors }\end{array}$ \\
\hline
\end{tabular}




\begin{tabular}{lll}
\hline Level & Process & Sub-process \\
\hline 4 & Performance measure- & Source: [30] \\
& ment & Establish a routine process involving: daily capacity planning meetings; monthly KPI status \\
& review; quarterly executive business reviews; and continual up-dating of key metrics/goals \\
& Design a proactive supplier scorecard-based rating system to drive continuous improvement \\
& Continuous improve- & Source: [30] \\
ment & Organizational collaborative improvement initiatives \\
& Benchmark \\
\hline
\end{tabular}

*Eliminated sub-processes

\section{Appendix 2: Model results}

\begin{tabular}{|c|c|c|}
\hline Process requirements & ABC company & $\mathrm{XYZ}$ company \\
\hline Level 1 & \multicolumn{2}{|l|}{$\mathrm{N} / \mathrm{A}$} \\
\hline \multicolumn{3}{|l|}{ Level 2} \\
\hline $\begin{array}{l}\text { Managerial commit- } \\
\text { ment and Strategic } \\
\text { intent }\end{array}$ & \multicolumn{2}{|c|}{$\begin{array}{l}\text { Answer: Yes } \\
\text { Clear missions and vision have been established. These clearly indicate the commitments and supports from } \\
\text { executives and managers to meet customers' expectations }\end{array}$} \\
\hline $\begin{array}{l}\text { Resource investment } \\
\text { and development }\end{array}$ & \multicolumn{2}{|c|}{$\begin{array}{l}\text { Answer: Yes } \\
\text { Financial and non-financial investments to develop human resource (such as training programs) and facilities } \\
\text { (such as latest technological equipment or ERP system) }\end{array}$} \\
\hline Rationalisation & \multicolumn{2}{|c|}{$\begin{array}{l}\text { Answer: Yes } \\
\text { By clearly defining the role in the chain, the appropriate type of production which is "make-to-order" with no- } \\
\text { finished good inventory have been clearly defined. The company's chain is simplified based on the customer } \\
\text { with assigned suppliers and service providers }\end{array}$} \\
\hline Internal alignment & $\begin{array}{l}\text { Answer: No } \\
\text { IE department was established in } 2013 \text { to implement } \\
\text { Lean manufacturing in order to reduce waste; however, } \\
\text { it only performed at the very three first steps of } 5 \text { S tool } \\
\text { The resultant inefficiency is apparent from on-site obser- } \\
\text { vations at ABC Company, with a high rate of work-in- } \\
\text { process (WIP), defects or stoppages }\end{array}$ & $\begin{array}{l}\text { Answer: Yes } \\
\text { IE department has been established from the } \\
\text { company's beginning. Lean manufacturing has suc- } \\
\text { cessfully been applied using many tools, such as 5S, } \\
\text { Kaizen, Kanban or Continuous Flow }\end{array}$ \\
\hline $\begin{array}{l}\text { Relationship and trust } \\
\text { building }\end{array}$ & $\begin{array}{l}\text { Answer: No } \\
\text { Customers must send a third-party to carry out product } \\
\text { inspections at ABC } \\
\text { Managers explain the reason for this distrust as follows: } \\
\text { "Company is losing many customers and struggling to } \\
\text { find new ones. We cannot meet the high requirements of } \\
\text { big customers because of an ineffective manufacturing } \\
\text { system. The current customers must send their representa- } \\
\text { tives to our system to jointly manage the manufacturing } \\
\text { process. We are not able to conduct self-inspection." - ABC } \\
\text { Lean manager }\end{array}$ & $\begin{array}{l}\text { Answer: Yes } \\
\text { XYZ has achieved factory self-inspection and meet } \\
\text { customers' audit with high standard. XYZ has long- } \\
\text { term relationships with customers }\end{array}$ \\
\hline $\begin{array}{l}\text { Information Flow and } \\
\text { System Integration }\end{array}$ & $\begin{array}{l}\text { Answer: No } \\
\text { ERP system has been established for three years. ABC } \\
\text { has developed its own basic modules for the ERP } \\
\text { system, such as Purchase, Human Resource, Inventory, } \\
\text { Sales and Marketing, and Production. Modules for } \\
\text { Finance and Accounting and Customer Relationship } \\
\text { Management (CRM) have not been developed yet. } \\
\text { Each module works separately and performs its own } \\
\text { data-processing function, and they do not constitute } \\
\text { an ERP integrated platform. Paper documentation is } \\
\text { used to complete processes and reporting }\end{array}$ & $\begin{array}{l}\text { Answer: Yes } \\
\text { XYZ Company has developed a world-class SAP ERP } \\
\text { application to access high quality data and boost } \\
\text { productivity, efficiency and profitability } \\
\text { Modern techniques with RFID on production shop- } \\
\text { floor to plan, track, monitor and manage order } \\
\text { status, quality and progress in real time } \\
\text { Electronic Data Interchange (EDI) is linked with } \\
\text { customers. XYZ has connected its ERP system with } \\
\text { customers }\end{array}$ \\
\hline
\end{tabular}




\begin{tabular}{|c|c|c|}
\hline Process requirements & ABC company & XYZ company \\
\hline Formalisation & $\begin{array}{l}\text { Answer: No } \\
\text { ABC Company has not built these rules yet, so a willing- } \\
\text { ness to share information is still limited because the } \\
\text { staffs do not know what to do and they are afraid of } \\
\text { the responsibility } \\
\text { "If we need data for requesting analysis, we do not know } \\
\text { which department is in charge of it and where to ask for. } \\
\text { Therefore, without a clear specification of information to } \\
\text { be shared, it takes time and efforts have complete and } \\
\text { accurate information." - } A B C \text { Lean manager }\end{array}$ & $\begin{array}{l}\text { Answer: Yes } \\
\text { XYZ has clear rules for information sharing with a } \\
\text { responsible person or department; type of informa- } \\
\text { tion shared and so on. These rules are documented } \\
\text { Therefore, the sharing information culture is also } \\
\text { established because the staffs are aware of their } \\
\text { roles as well as their responsibilities. Especially, } \\
\text { confidential information such as information of } \\
\text { special design or technique is also shared based on } \\
\text { commitments and trust }\end{array}$ \\
\hline
\end{tabular}

Level 3

Goal congruence

Decision synchronisation

Incentive alignment

Resource sharing

Joint knowledge creation

Collaborative communication

Information sharing

Level 4

Performance measurement

Answer: Yes

$A B C$ and $X Y Z$ are members of the Vietnam Textile and Apparel Association (VITAS) and responsible for the integration and growth of the Vietnam's textile and apparel sector. Both companies have agreements on collaboration among partners which are ruled by meeting the customers' satisfaction

\section{Answer: Yes}

Processes of decision synchronization and incentive alignment are presented through jointly working out on solutions on delivery date, on late delivery (such as expanding the due date or sharing cost for airship) or for sampling development and so on

Answer: Yes

Resource sharing is made between company and customers including technical supports, jointly searching and acquiring new techniques for product design and production or jointly managing the production process. Customers send their representatives to the manufacturers during production time to support and timely solve the problems

Answer: No

The lack of ability and capability to collaborate (level 2) leads to insufficient Information Sharing and Collaborative Communication. This incomplete reporting does not occur in real time, increasing the chances of contradictory data that causes redundancy. $A B C$ is not able to exchange information timely and accurately within the organization as well as with partners [52]

"Sale department is not updated with the current production capacity status; so when we negotiate the due date for an order, we make decision based on the planning documents. This can cause the wrong date and lead to the late delivery."-ABC Sale manager

\section{Answer: No}

Performance measurement has not yet been established at $A B C$. At the moment, raw data have been recorded in the electronic system; however, they have not been analysed for management purpose yet [52] "Raw data is recorded but have not been used for any analysis to evaluate the performance. Improvement activities cannot be conducted because we are trying to standardize the system." - ABC Lean manager
Answer: Yes

By creating the ability and capability for organisation to share information, has exchanged relevant, timely, accurate and complete information within the company and the operations are very smooth and problems are solved very quickly

Level 5

Continuous improvement
Answer: No

Continuously improving collaboration capability has not been recorded in practice [23], and as such level 5 is considered as an ideal level for the industry. In this study, XYZ has not performed activities of level 5 for SCC process yet

Level 1
Answer: Yes

$\mathrm{XYZ}$ has built a very good KPI system, which is customers' requirement for auditing for each department. Data are processed daily and meetings are held weekly to continuously up-date key metrics/ goals:

"We establish goals for productivity, measure through KPI and manage the system quantitatively. Continuous improvement Kaizen is constantly performed."$X Y Z I E$ manager 


\section{References}

1. Skjoett-Larsen T, Thernøe C, Andresen C (2003) Supply chain collaboration: theoretical perspectives and empirical evidence. Int J Phys Distrib Logist Manag 33(6):531-549. https:// doi.org/10.1108/09600030310492788

2. Cao M, Vonderembse MA, Zhang Q, Ragu-Nathan T (2010) Supply chain collaboration: conceptualisation and instrument development. Int J Prod Res 48(22):6613-6635

3. Min S et al (2005) Supply chain collaboration: what's happening? Int J Logist Manag 16(2):237-256. https://doi.org/10.1108/09574 090510634539

4. Schuh G, Sauer A, Doering S (2008) Managing complexity in industrial collaborations. Int J Prod Res 46(9):2485-2498

5. Bititci US, Garengo P, Ates A, Nudurupati SS (2015) Value of maturity models in performance measurement. Int J Prod Res 53(10):3062-3085

6. Cao M, Zhang Q (2011) Supply chain collaboration: impact on collaborative advantage and firm performance. J Oper Manag 29(3):163-180. https://doi.org/10.1016/j.jom.2010.12.008

7. Kampstra R, Ashayeri J, Gattorna J (2006) Realities of supply chain collaboration. Int J Logist Manag 17(3):312-330

8. Cao M, Zhang Q (2013) Supply chain collaboration: roles of interorganizational systems, trust, and collaborative culture. Springer, London

9. Holweg M, Disney S, Holmström J, Småros J (2005) Supply chain collaboration: making sense of the strategy continuum. Eur Manag J 23(2):170-181

10. Frohlich MT, Westbrook R (2001) Arcs of integration: an international study of supply chain strategies. J Oper Manag 19(2):185-200

11. Boughzala I, De Vreede G-J (2012) A collaboration maturity model: development and exploratory application. In: 2012 45th Hawaii international conference on system science (HICSS), IEEE, pp 306-315

12. Mackelprang AW, Robinson JL, Bernardes E, Webb GS (2014) The relationship between strategic supply chain integration and performance: a meta-analytic evaluation and implications for supply chain management research. J Bus Logist 35(1):71-96

13. Power $D$ (2005) Supply chain management integration and implementation: a literature review. Supply Chain Manag Int J 10(4):252-263

14. Akyuz GA, Erkan TE (2010) Supply chain performance measurement: a literature review. Int J Prod Res 48(17):5137-5155. https ://doi.org/10.1080/00207540903089536

15. Ho D, Kumar A, Shiwakoti N (2016) Maturity model for supply chain collaboration: CMMI approach. In: 2016 IEEE international conference on industrial engineering and engineering management (IEEM), IEEE, pp 845-849

16. Fabbe-Costes N, Jahre M (2008) Supply chain integration and performance: a review of the evidence. Int J Logist Manag 19(2):130-154

17. Rodrigues AM, Stank TP, Lynch DF (2004) Linking strategy, structure, process, and performance in integrated logistics. J Bus Logist 25(2):65-94

18. Wu L, Chuang C-H, Hsu C-H (2014) Information sharing and collaborative behaviors in enabling supply chain performance: a social exchange perspective. Int J Prod Econ 148:122-132

19. Jakhar SK (2015) Performance evaluation and a flow allocation decision model for a sustainable supply chain of an apparel industry. J Clean Prod 87:391-413

20. Sen A (2008) The US fashion industry: a supply chain review. Int J Prod Econ 114(2):571-593
21. Kanda A, Deshmukh S (2008) Supply chain coordination: perspectives, empirical studies and research directions. Int J Prod Econ 115(2):316-335

22. Mehrjoo M, Pasek ZJ (2016) Risk assessment for the supply chain of fast fashion apparel industry: a system dynamics framework. Int J Prod Res 54(1):28-48

23. Jin B (2006) Performance implications of information technology implementation in an apparel supply chain. Supply Chain Manag Int J 11(4):309-316

24. Agarwal A, Shankar R, Tiwari M (2007) Modeling agility of supply chain. Ind Mark Manag 36(4):443-457

25. Kim JO, Traore MK, Warfield C (2006) The textile and apparel industry in developing countries. Text Prog 38(3):1-64. https:// doi.org/10.1533/tepr.2006.0003

26. Gereffi G, Memedovic O (2003) The global apparel value chain: what prospects for upgrading by developing countries. United Nations Industrial Development Organization, Vienna

27. Lopez-Acevedo G, Robertson R (2016) Stitches to Riches?: Apparel employment, trade, and economic development in South Asia. World Bank Publications, Washington, DC

28. Muckstadt JA, Murray DH, Rappold JA, Collins DE (2001) Guidelines for collaborative supply chain system design and operation. Inf Syst Front 3(4):427-453

29. Matopoulos A, Vlachopoulou M, Manthou V, Manos B (2007) A conceptual framework for supply chain collaboration: empirical evidence from the agri-food industry. Supply Chain Manag Int J 12(3):177-186. https://doi.org/10.1108/13598540710742491

30. Fawcett SE, Magnan GM, McCarter MW (2008) A three-stage implementation model for supply chain collaboration. J Bus Logist 29(1):93-112. https://doi.org/10.1002/j.2158-1592.2008. tb00070.x

31. Soosay CA, Hyland P (2015) A decade of supply chain collaboration and directions for future research. Supply Chain Manag Int J 20(6):613-630. https://doi.org/10.1108/SCM-06-2015-0217

32. Stank TP, Keller SB, Daugherty PJ (2001) Supply chain collaboration and logistical service performance. J Bus Logist 22(1):29-48

33. Simatupang TM, Sridharan R (2002) The collaborative supply chain. Int J Logist Manag 13(1):15-30

34. Xu K, Dong Y, Evers PT (2001) Towards better coordination of the supply chain. Transp Res Part E Logist Transp Rev 37(1):35-54

35. Flynn BB, Huo B, Zhao X (2010) The impact of supply chain integration on performance: a contingency and configuration approach. J Oper Manag 28(1):58-71

36. Spekman RE, Kamauff JW Jr, Myhr N (1998) An empirical investigation into supply chain management: a perspective on partnerships. Supply Chain Manag Int J 3(2):53-67. https://doi. org/10.1108/13598549810215379

37. Crosby PB (1979) Quality is free. McGraw-Hill, New York

38. Boughzala I, De Vreede T, Nguyen C, De Vreede G-J (2014) Towards a maturity model for the assessment of ideation in crowdsourcing projects. In: 2014 47th Hawaii international conference on system sciences (HICSS), IEEE, pp 483-490

39. Looy AV, Backer MD, Poels G (2014) A conceptual framework and classification of capability areas for business process maturity. Enterp Inf Syst 8(2):188-224

40. Wendler R (2012) The maturity of maturity model research: a systematic mapping study. Inf Softw Technol 54(12):1317-1339

41. Ngai E, Chau D, Poon J, To C (2013) Energy and utility management maturity model for sustainable manufacturing process. Int J Prod Econ 146(2):453-464

42. Jiang JJ, Klein G, Hwang HG, Huang J, Hung SY (2004) An exploration of the relationship between software development process maturity and project performance. Inf Manag 41(3):279288. https://doi.org/10.1016/s0378-7206(03)00052-1

43. Team CP (2010) CMMI for acquisition version 1.3. Lulu.com 
44. Ho D, Kumar A, Shiwakoti N (2019) A literature review of supply chain collaboration mechanisms and their impact on performance. Eng Manag J 31(1):47-68

45. Simatupang TM, Sridharan R (2005) The collaboration index: a measure for supply chain collaboration. Int J Phys Distrib Logist Manag 35(1):44-62. https://doi.org/10.1108/096000305105774 21

46. Ngai EWT, Cheng TCE, Ho SSM (2004) Critical success factors of web-based supply-chain management systems: an exploratory study. Prod Plan Control 15(6):622-630. https://doi. org/10.1080/09537280412331283928

47. Chen IJ, Paulraj A (2004) Towards a theory of supply chain management: the constructs and measurements. J Oper Manag 22(2):119-150

48. Fawcett SE, Wallin C, Allred C, Fawcett AM, Magnan GM (2011) Information technology as an enabler of supply chain collaboration: a dynamic-capabilities perspective. J Supply Chain Manag 47(1):38-59. https://doi.org/10.1111/j.1745-493X.2010.03213.x

49. McCormack K, Ladeira MB, de Oliveira MPV (2008) Supply chain maturity and performance in Brazil. Supply Chain Manag Int J 13(4):272-282. https://doi.org/10.1108/13598540810882161

50. Chan FTS, Chong AY-L, Zhou L (2012) An empirical investigation of factors affecting e-collaboration diffusion in SMEs. Int J Prod Econ 138(2):329-344. https://doi.org/10.1016/j.ijpe.2012.04.004

51. Chong AY-L, Ooi K-B, Sohal A (2009) The relationship between supply chain factors and adoption of e-collaboration tools: an empirical examination. Int J Prod Econ 122(1):150-160

52. Lawshe $\mathrm{CH}$ (1975) A quantitative approach to content validity. Pers Psychol 28(4):563-575

53. Meng X, Sun M, Jones M (2011) Maturity model for supply chain relationships in construction. J Manag Eng 27(2):97-105

54. Garcia Reyes H, Giachetti R (2010) Using experts to develop a supply chain maturity model in Mexico. Supply Chain Manag Int J 15(6):415-424

55. ITPC (2015) Vietnam's garment and textile industry. Investment and Trade Promotion Centre, Ho Chi Minh City

56. Bruce M, Daly L, Towers N (2004) Lean or agile: a solution for supply chain management in the textiles and clothing industry? Int J Oper Prod Manag 24(2):151-170

57. Voss C, Tsikriktsis N, Frohlich M (2002) Case research in operations management. Int J Oper Prod Manag 22(2):195-219

58. Yin RK (2013) Case study research: design and methods. Sage publications, Thousand Oaks

59. Chen H, Daugherty PJ, Landry TD (2009) Supply chain process integration: a theoretical framework. J Bus Logist 30(2):27-46

60. Tsanos CS, Zografos KG, Harrison A (2014) Developing a conceptual model for examining the supply chain relationships between behavioural antecedents of collaboration, integration and performance. Int J Logist Manag 25(3):418-462

61. Germain R, lyer KN (2006) The interaction of internal and downstream integration and its association with performance. J Bus Logist 27(2):29-52

62. Williams BD, Roh J, Tokar T, Swink M (2013) Leveraging supply chain visibility for responsiveness: the moderating role of internal integration. J Oper Manag 31(7):543-554

63. Koufteros X, Vonderembse M, Jayaram J (2005) Internal and external integration for product development: the contingency effects of uncertainty, equivocality, and platform strategy. Decis Sci 36(1):97-133

64. Cagliano R, Caniato F, Spina G (2006) The linkage between supply chain integration and manufacturing improvement programmes. Int J Oper Prod Manag 26(3):282-299

65. Glenn Richey R Jr, Chen H, Upreti R, Fawcett SE, Adams FG (2009) The moderating role of barriers on the relationship between drivers to supply chain integration and firm performance. Int J Phys Distrib Logist Manag 39(10):826-840
66. Sanders NR, Premus R (2005) Modeling the relationship between firm IT capability, collaboration, and performance. J Bus Logist 26(1):1-23

67. Bharadwaj AS (2000) A resource-based perspective on information technology capability and firm performance: an empirical investigation. MIS Q 24:169-196

68. Kearns GS, Lederer AL (2003) A resource-based view of strategic IT alignment: how knowledge sharing creates competitive advantage. Decis Sci 34(1):1-29

69. Zhu Q, Sarkis J (2004) Relationships between operational practices and performance among early adopters of green supply chain management practices in Chinese manufacturing enterprises. J Oper Manag 22(3):265-289

70. Samson D, Terziovski M (1999) The relationship between total quality management practices and operational performance. $J$ Oper Manag 17(4):393-409

71. Brown S, Blackmon K, Cousins P, Maylor H (2013) Operations management: policy, practice and performance improvement. Routledge, Abingdon

72. Bromiley P, Rau D (2016) Operations management and the resource based view: another view. J Oper Manag 41:95-106

73. Stevens GC (1989) Integrating the supply chain. Int J Phys Distrib Logist Manag 19(8):3-8

74. Kim D-Y (2013) Relationship between supply chain integration and performance. Oper Manag Res 6(1-2):74-90

75. Droge C, Jayaram J, Vickery SK (2004) The effects of internal versus external integration practices on time-based performance and overall firm performance. J Oper Manag 22(6):557-573

76. Zailani S, Rajagopal P (2005) Supply chain integration and performance: US versus East Asian companies. Supply Chain Manag Int J 10(5):379-393

77. Fliedner G (2003) CPFR: an emerging supply chain tool. Ind Manag Data Syst 103(1):14-21

78. Gimenez C, Ventura E (2005) Logistics-production, logistics-marketing and external integration: their impact on performance. Int J Oper Prod Manag 25(1):20-38

79. Rosenzweig ED, Roth AV, Dean JW (2003) The influence of an integration strategy on competitive capabilities and business performance: an exploratory study of consumer products manufacturers. J Oper Manag 21(4):437-456

80. Zhao X, Huo B, Selen W, Yeung JHY (2011) The impact of internal integration and relationship commitment on external integration. J Oper Manag 29(1-2):17-32

81. Huo B (2012) The impact of supply chain integration on company performance: an organizational capability perspective. Supply Chain Manag Int J 17(6):596-610

82. Fawcett SE, Magnan GM (2002) The rhetoric and reality of supply chain integration. Int J Phys Distrib Logist Manag 32(5):339-361

83. Barratt $M$ (2004) Understanding the meaning of collaboration in the supply chain. Supply Chain Manag Int J 9(1):30-42. https ://doi.org/10.1108/13598540410517566

84. Won Lee C, Kwon I-WG, Severance D (2007) Relationship between supply chain performance and degree of linkage among supplier, internal integration, and customer. Supply Chain Manag Int J 12(6):444-452

85. Shtub A, Karni R (2010) ERP: the dynamics of supply chain and process management. Springer, Berlin

86. Berger A (1997) Continuous improvement and kaizen: standardization and organizational designs. Integr Manuf Syst 8(2):110-117

87. Alfalla-Luque R, Medina-Lopez C, Dey PK (2013) Supply chain integration framework using literature review. Prod Plan Control 24(8-9):800-817

Publisher's Note Springer Nature remains neutral with regard to jurisdictional claims in published maps and institutional affiliations. 